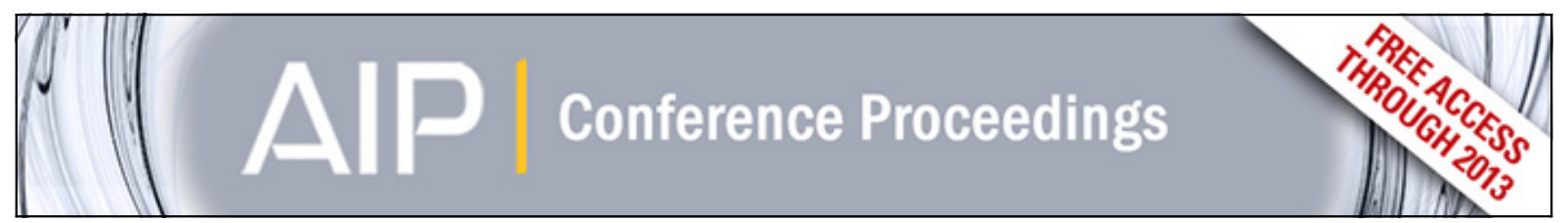

The effect of nanofiber based filter morphology on bacteria deactivation during water filtration

Dusan Kimmer, Ivo Vincent, Jaroslav Lev, Libor Kalhotka, Premysl Mikula, Radka Korinkova, Wannes Sambaer, and Martin Zatloukal

Citation: AIP Conference Proceedings 1526, 316 (2013); doi: 10.1063/1.4802626

View online: http://dx.doi.org/10.1063/1.4802626

View Table of Contents: http://scitation.aip.org/content/aip/proceeding/aipcp/1526?ver=pdfcov

Published by the AIP Publishing 


\title{
The Effect of Nanofiber Based Filter Morphology on Bacteria Deactivation during Water Filtration
}

\author{
Dusan Kimmer $^{\mathrm{a}}$, Ivo Vincent ${ }^{\mathrm{a}}$, Jaroslav Lev ${ }^{\mathrm{b}}$, Libor Kalhotka ${ }^{\mathrm{c}}$, Premysl \\ Mikula $^{\mathrm{d}}$, Radka Korinkova ${ }^{\mathrm{e}}$, Wannes Sambaer ${ }^{\mathrm{f}, \mathrm{g}}$, Martin Zatloukal ${ }^{\mathrm{f}, \mathrm{g}}$ \\ ${ }^{a}$ SPUR a.s., trida Tomase Bati 299, Louky, 76302 Zlin, Czech Republic \\ ${ }^{b}$ ASIO spol. s r.o., Turanka 1, 62700 Brno, Czech Republic \\ ${ }^{c}$ Mendel University in Brno, Faculty of Agronomy, Zemedelska 1, 61300 Brno, Czech Republic \\ ${ }^{d}$ Institute of Botany of the ASCR, Lidicka 25/27, 60200 Brno, Czech Republic \\ ${ }^{e}$ COC s.r.o., 53354 Rybitvi, Czech Republic \\ ${ }^{f}$ Polymer Centre, Faculty of Technology, Tomas Bata University in Zlin, \\ nam. T. G. Masaryka 275, 76272 Zlin, Czech Republic \\ ${ }^{g}$ Centre of Polymer Systems, University Institute, Tomas Bata University in Zlin, \\ Nad Ovcirnou 3685, 76001 Zlin, Czech Republic
}

\begin{abstract}
Procedures permitting to prepare homogeneous functionalized nanofibre structures based on polyurethanes modified by phthalocyanines (PCs) by employing a suitable combination of variables during the electrospinning process are presented. Compared are filtration and bacteria deactivation properties of open and planar nanostructures with PCs embedded into polyurethane chain by a covalent bond protecting the release of active organic compound during the filtration process. Finding that the morphology of functionalized nanofibre structures have an effect on bacterial growth was confirmed by microbiological and physico-chemical analyses, such as the inoculation in a nutrient agar culture medium and flow cytometry.
\end{abstract}

Keywords: Nanofibre, Nanostructure, Electrospinning, Phthalocyanines, Bacteria deactivation. PACS: 81.20.Ka， 81.16.-c， 81.16.Be， 81.07.-b， 81.05.Lg，61.46.-w，62.23.Kn，62.23.St, 31.10. + Z, 33.15.Fm

\section{INTRODUCTION}

At present, the requirements on elimination of ultrafine particles by microfiltration and ultrafiltration are increased by a demand for materials capable of not only capturing but also deactivating bacteria and viruses from air and water [1,2]. The filtration materials capable of deactivating bacteria during filtration process will always offer an advantage as regards elimination of microorganisms in comparison with the materials permitting a barrier type of microorganism capture only.

A correct assessment of antibacterial properties of filtration nanomaterials requires an assessment accuracy and comparison of the results obtained using preferably several specific analyses. We have chosen the microbiological one (cultivation on a selective medium), physical-chemical (flow cytometry) and also fluorescent microscopy. By combining results obtained by the above methods not only filtration efficiency of nanostructures but also bacteria deactivation efficiency can be evaluated.

Novel Trends in Rheology $V$

AIP Conf. Proc. 1526, 316-325 (2013); doi: 10.1063/1.4802626

(C) 2013 AIP Publishing LLC 978-0-7354-1151-7/\$30.00 


\section{EXPERIMENTAL}

\section{Materials}

A modified polyurethane (PU) solution in dimethyl formamide for electrostatic spinning was prepared from diisocyanate, polyesterdiol, 1,4 butane diol (BD) and phthalocyanine (PC) containing amino or hydroxyl group in at the temperature of $90^{\circ} \mathrm{C}$ for a time period of 6 hours. Per partes method of synthesis was used. The solution prepared in this way was diluted with DMF to a viscosity of $1.3 \mathrm{~Pa}$.s and its conductivity was increased to $150 \mu \mathrm{S} . \mathrm{cm}^{-1}$.

Phthalocyanines (tetrabenzo-fused 5,10,15,20-tetraazaporphyrins) belong to the group of photosensitizers capable of generating singlet oxygen and other reactive oxygen species upon interaction with light of suitable wavelength in the presence of oxygen. Singlet oxygen and other reactive oxygen species have strong biocidal effect on algae, bacteria, fungi and yeasts.

For model filtration a suspension of Escherichia coli (CCM2024 non-pathogenic strain) was used.

\section{Filter Sample Preparation by Electrospinning Process}

Nanofibre layers were prepared from polymeric solutions with a commercially available NanoSpiderTM machine (Elmarco s.r.o. Liberec, Czech Republic, http://www.elmarco.com/) equipped with a patented rotating electrode with 3 cotton cords spinning elements (PCT/CZ2010/000042) and/or SpinLine 120 equipment (SPUR a.s., Zlín, Czech republic, http://www.spur-nanotechnologies.cz) using nanofibres forming jets. The experimental conditions were as follows: relative humidity: $28 \%$, temperature: $23^{\circ} \mathrm{C}$, electric voltage applied to PU solution: $75 \mathrm{kV}$, distance between electrodes: $210 \mathrm{~mm}$, speed of supporting textile collecting nanofibres: $0.16 \mathrm{~m} \cdot \mathrm{min}^{-1}$. Nanofibres were collected on polypropylene (PP), polyester or viscose nonwoven textiles.

\section{Proving Embedding of PC in PU Chains}

Thin films were cast from samples of aqueous extracts of modified nanostructures with embedded and unembedded PC on a silica substrate and subsequently FTIR spectra were measured with the aid of Nicolet IS5 spectrometer using a wave number ranging from 800 to $4000 \mathrm{~cm}^{-1}$.

\section{Filter Sample Characterization}

Nanofibre-based filter prepared by the electrospinning process was characterized by a scanning electron microscope (SEM, Vega 3, Tescan, Czech Republic). In some cases the SEM images obtained were consequently used to determine fibre diameter distribution and pore size distribution by using the recently developed UTBsoft Filtration v1.0.1 simulation software utilizing digital image analysis technique described in [3-7]. 


\section{Laboratory Water-filtration Equipment}

For experiments the filter was lumminated by LED diode (wave length $660 \mathrm{~nm}$ ) placed in a distance of $3 \mathrm{~cm}$ from the filter.

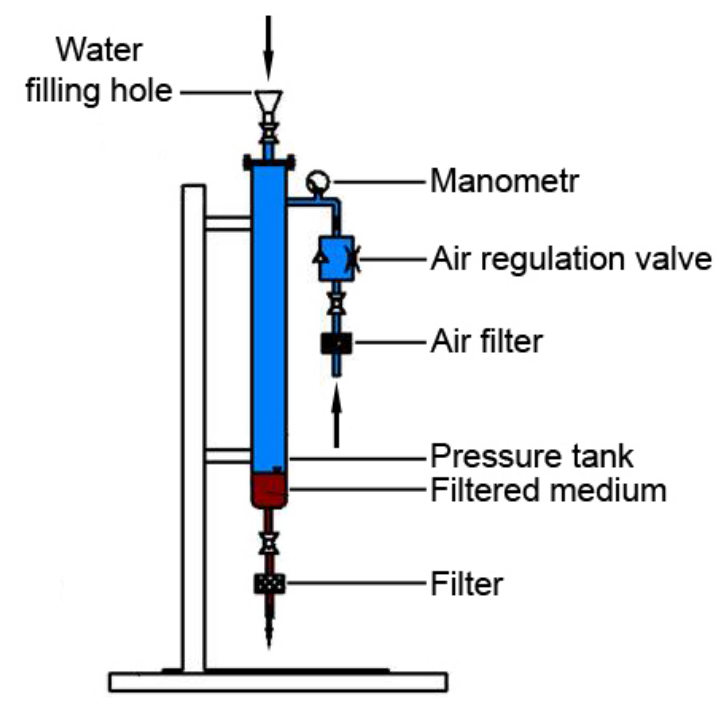

FIGURE 1. Model waste water filtration set up.

\section{Characterization of Antibacterial Properties}

\section{Microbiological Analysis}

A method used to determine number of microorganisms by cultivation on a nutrient medium is a standard technique prescribed by standards (namely EN ISO 6222:1999 or EN ISO 9308-1:2000). Employing this method it is possible to cultivate the sort of microbiological organism (contamination) under investigation and to determine quantity of live cultivable bacteria. Decimal dilutions of filtered model solution were prepared and $1 \mathrm{ml}$ of relevant dilution was inoculated onto sterile Petri dish filled with nutrient medium - VRBLagar (Biokar Diagnostics, France). The samples were incubated for $24 \mathrm{hrs}$ at $37^{\circ} \mathrm{C}$. Grown colonies of Escherichia coli were counted and the number of bacteria were calculated and expressed as CFU.ml ${ }^{-1}$.

\section{Flow Cytometry (FCM)}

Flow cytometry represents one of the most prospective analytical methods in aquatic microbiology, ecology and ecotoxicology. FCM enables not only fast and accurate counting of cells, but also a determination of a number of physiological, genetical and other parameters of cell populations contained in sample suspensions based on their optical characteristics. In our study, bacteria were enumerated using CyFlow ML flow cytometer (Partec, Muenster, Germany) equipped with blue excitation laser $(\lambda=488 \mathrm{~nm})$ and four optical parameters (forward- and side scatters as well as two fluorescent channels). Before the measurement started, samples were 
stained with SYBR Green I fluorescent stain and incubated for 15 minutes in the dark [9]. SYBR Green enters the cells of all bacteria regardless their physiological state and binds to cellular nucleic acids. After staining, green fluorescent bacteria are easily distinguishable on flow cytometric diagrams from the background, which enables determination of bacterial counts (or rather concentration) in analyzed sample. In addition to that, dual staining of samples by SYBR Green I and propidiumiodide (PI) (with 15 minutes of incubation in the dark) was performed to measure bacterial membrane integrity [10]. Unlike SYBR Green I, PI may enter the cell only in a case of cell membrane damage. Since PI possess red fluorescence, on flow cytometric histograms, cells with damaged cell membrane can be discriminated from intact cells based on their high red and low green fluorescence (on the contrary, intact cells have high green and negligible red fluorescence). Cells with damaged cell membrane can be considered as "dead", as they are not able to reproduce or even face the adverse insults from their environment, which, sooner or later, leads to their lysis.

\section{Analysis of Decomposition Products of Deactivating Action of PC}

\section{UV-VIS Spectrophotometry}

UV-VIS spectrophotometry was used to determine protein components and concentration of DNA, i.e. possible products of deactivating action of PC on bacteria (proteins, toxins) during filtration of air. The analyses were performed behind the filtration material (in bubblers and on final High-Efficiency Particulate Air /HEPA/ filters) on SmartSPec Plus Spectrofotometer (Bio-Rad, Sergate, Italy).

At the wavelength of $280 \mathrm{~nm}$ no measurable values of the protein components were obtained. This means that the bacteria deactivation does not lead to a complete decomposition of the bacteria. Bacteria form a filtration cake on the surface of and inside the nanostructures. Values of DNA concentrations at $260 \mathrm{~nm}$ were comparable with the concentrations of the bacteria detected with other analytical methods.

\section{RESULTS AND DISCUSSION}

All currently marketed biocide-modified polymer materials are bulk or surface treated. Compatibility with the binder is provided mostly by Van der Walls forces only or is not provided at all. Therefore, the biocides can be removed from the polymers by the stream of the media filtered or by extraction into water $[1,2]$.

In order to eliminate the above shortcomings a procedure can be used based on nanostructures formed by nanofibres having a diameter from $50 \mathrm{~nm}$ to $500 \mathrm{~nm}$ and a pore size (a diameter of inscribed spheres) ranging from $200 \mathrm{~nm}$ to $1500 \mathrm{~nm}$, which are highly efficient in capturing microorganisms and bacteria, in filtering air as well as in capture of viruses. The biocidal substances are embedded in the polymer being spinned (primarily polyurethane) directly with a covalent bond so that they could not escape spontaneously from the filtration materials. The covalent bond between the molecule of the biocide and that of the polyurethane (PU) is formed during the polyadduct synthesis proper and results from reaction of the isocyanate group located at the end of the PU chain with acidic hydrogen of the amino group (Eg. 1 -during 
which urea bonds are formed), from reaction of the hydroxy group (Eq. 2 - during which urethane bonds are formed), or from reaction of carboxy group (during which amides are formed - Eq. 3). The amino, hydroxy and/or carboxy groups being a part of the biocidal molecule.

$$
\begin{aligned}
& W^{\mathrm{PU}} \leadsto \mathrm{W}^{\mathrm{NCO}}+\mathrm{H}_{2} \mathrm{~N}-\mathrm{PC} \longrightarrow \mathrm{W}^{\mathrm{PU}} \longrightarrow \mathrm{W}^{\mathrm{NHCONH}-\mathrm{PC}}
\end{aligned}
$$

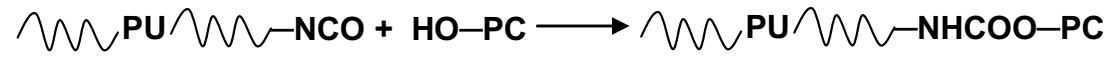

$$
\begin{aligned}
& W^{\mathrm{PU}} \leadsto \text { W-NCO + HOOC-PC} \longrightarrow\left(W^{\mathrm{PU}} \leadsto \text { W-NHCOOOC-PC}\right) \longrightarrow \\
& \longrightarrow \mathrm{WPU}^{\mathrm{P}} \mathrm{W}-\mathrm{NHCO}-\mathrm{PC}+\mathrm{CO}_{2}
\end{aligned}
$$

\section{Embedding of PC into Nanostructures}

The highest efficiencies of PC embedding into PU were achieved in case of PC containing a free amino group. The FTIR spectra in Figure 2 compare PU modified in bulk with unembedded sulphonated PC and PU with embedded cationic PC with substituent containing amino group. The absorption peaks at wave numbers of $1723 \mathrm{~cm}^{-1}\left(\mathrm{C}=\mathrm{O}\right.$ from urethane bond) and $1589 \mathrm{~cm}^{-1}(\mathrm{~N}-\mathrm{H}$ group originating from the urea bond) show formation of an embedding into the PU chain [8].

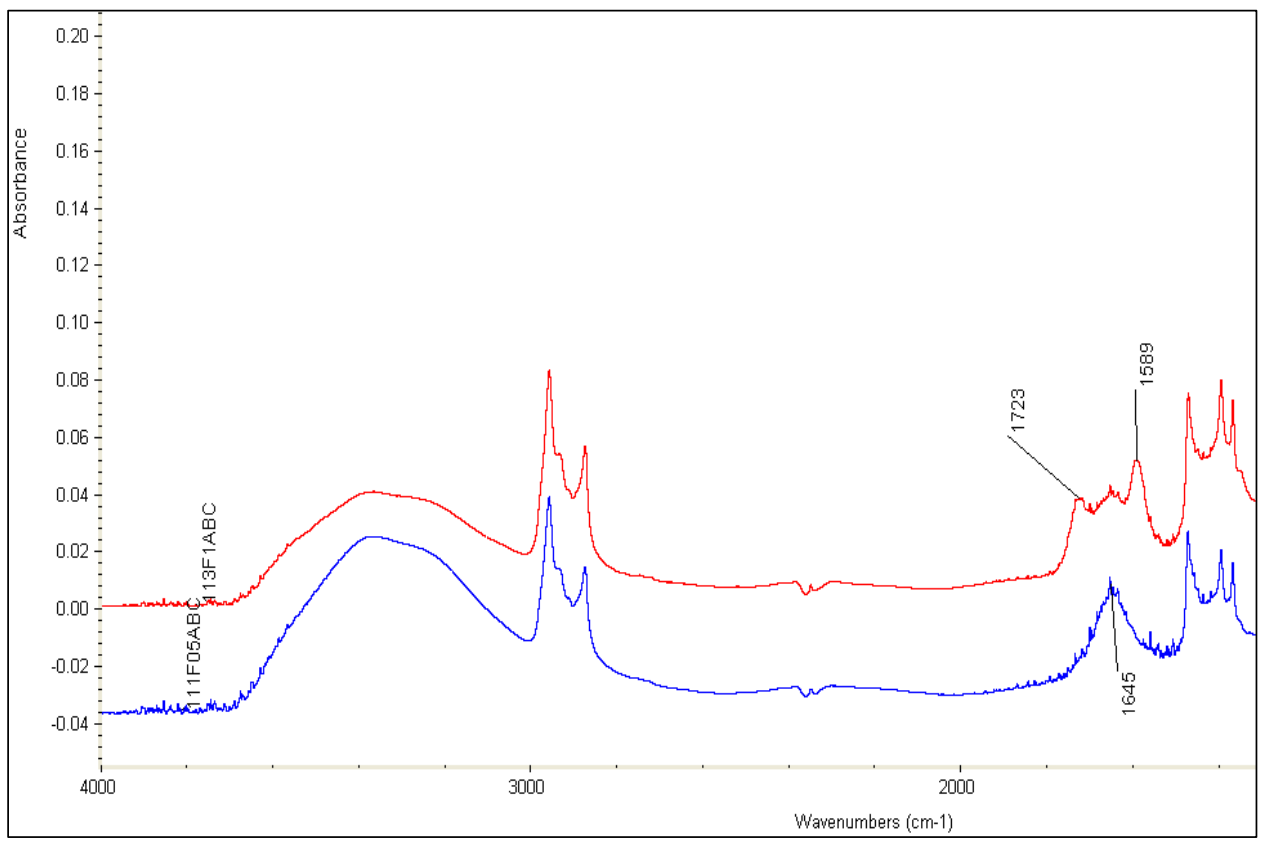

FIGURE 2. FTIR spectra of PC embedded (red) and unembedded (blue) into PU chains. 


\section{Model Filtration of Water}

Table 1 presents results of deactivation efficiency of PU nanofibres modified by 1 mass percent of PC for filtrations of model suspensions of Escherichia coli bacteria in water. The starting Escherichia coli suspension contained $8.33 \cdot 10^{6}$ of colony forming units CFU.ml ${ }^{-1}$ determined by the cultivation method or $6.89 \cdot 10^{6}$ cells. $\mathrm{ml}^{-1}$ determined by flow cytometry.

TABLE 1. Filtration ${ }^{1)}$ of a model sample of Escherichia coli bacteria in water through PC-modified PU nanostructures.

\begin{tabular}{|c|c|c|c|c|}
\hline \multirow[b]{2}{*}{ Sample } & \multirow[b]{2}{*}{$\begin{array}{l}\text { Mass per } \\
\text { square area }\end{array}$} & \multirow[b]{2}{*}{ Analyzed place } & \multicolumn{2}{|c|}{ Flow cytometry } \\
\hline & & & $\begin{array}{c}\text { Deactivated }^{2)} \\
(\%)\end{array}$ & $\begin{array}{c}\text { Substance balance } \\
\text { (cells in front of/cells on } \\
\text { and behind filter) }\end{array}$ \\
\hline \multirow{3}{*}{1} & \multirow{3}{*}{$3.0 \mathrm{~g} / \mathrm{m}^{2}$} & starting dispersion & nd & $6.89 \cdot 10^{9}$ \\
\hline & & filter - shake out & 52.08 & 1 \\
\hline & & filtrate & 65.31 & $4.79 \cdot 10^{9}$ \\
\hline \multirow{3}{*}{2} & \multirow{3}{*}{$3.0 \mathrm{~g} / \mathrm{m}^{2}$} & starting dispersion & nd & $5.37 \cdot 10^{9}$ \\
\hline & & filter - shake out & nd & 1 \\
\hline & & filtrate & 5.98 & $1.45 \cdot 10^{9}$ \\
\hline
\end{tabular}

1) At the pressure of 1 bar

${ }^{2)}$ Membrane integrity (viability) measured after 24 hours of storing the samples in dark

The deactivation efficiency both in the shake-out and the filtrate in case of Sample 1 is relatively high, the illumination (exposure to light) has been 10 min only. Comparison with Samples 1 and 2 shows also an influence of the nanostructure morphology. The Samples 1 and 2 differ also by the space arrangement of the nanostructures as can be concluded from the filtration efficiencies achieved at identical mass per square area.

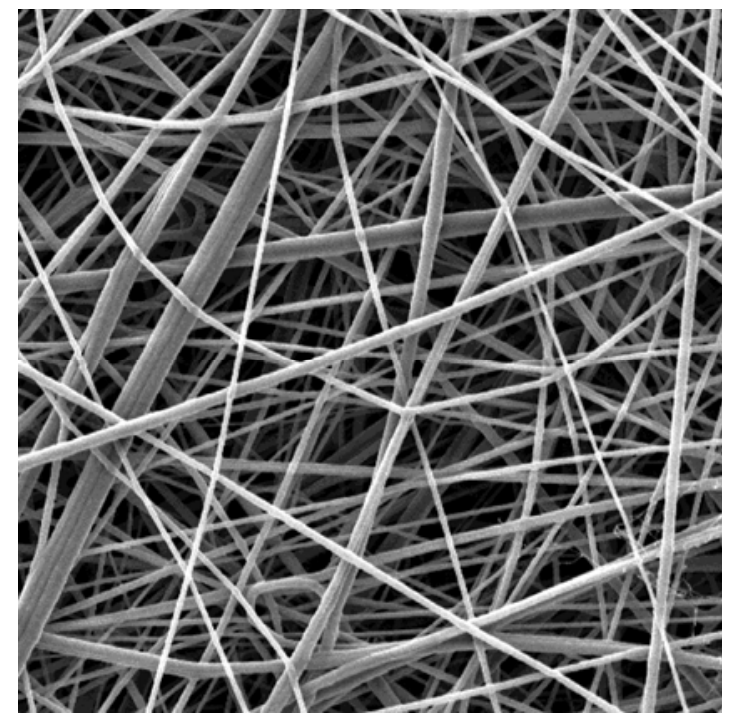

FIGURE 3. Open nanostructure of Sample 1 with a wide distribution of nanofibre diameters, magnification $5,000 \times$. 


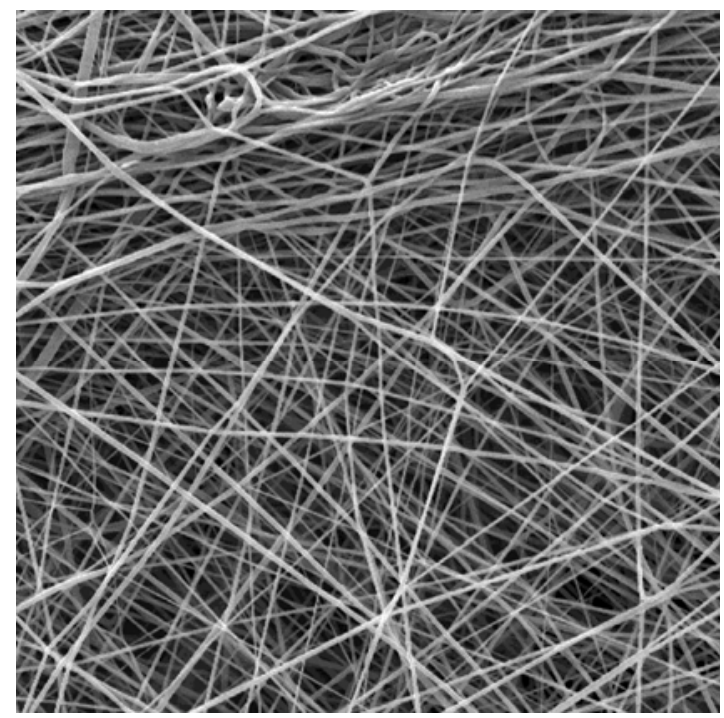

FIGURE 4. Planar Nanostructure of Sample 2, Magnification 5,000×.

Open structure (Figure 3) in comparison with the planar one (Figure 4) can assure a more perfect contact of bacteria with nanofibres and thus increase also the deactivation capacities during passage of the bacteria through the nanostructure (Figure 5). The space structure will be more passable (maximum pore size in nanostructure $D=2129.8 \mathrm{~nm}$ ) and will let pass through more dead but also live bacteria. A filtration cake is formed quickly on a filter with a uniform distribution (maximum pore size in nanostructure $D=1250.0 \mathrm{~nm}$ ) of nanofibres (Figure 6). The best information about bacteria sizes gives the Figures 5 and 6 . The filtration cake formed prevents the required contact of filtrated bacteria with the active surface of the nanostructure and hinders also its illumination.

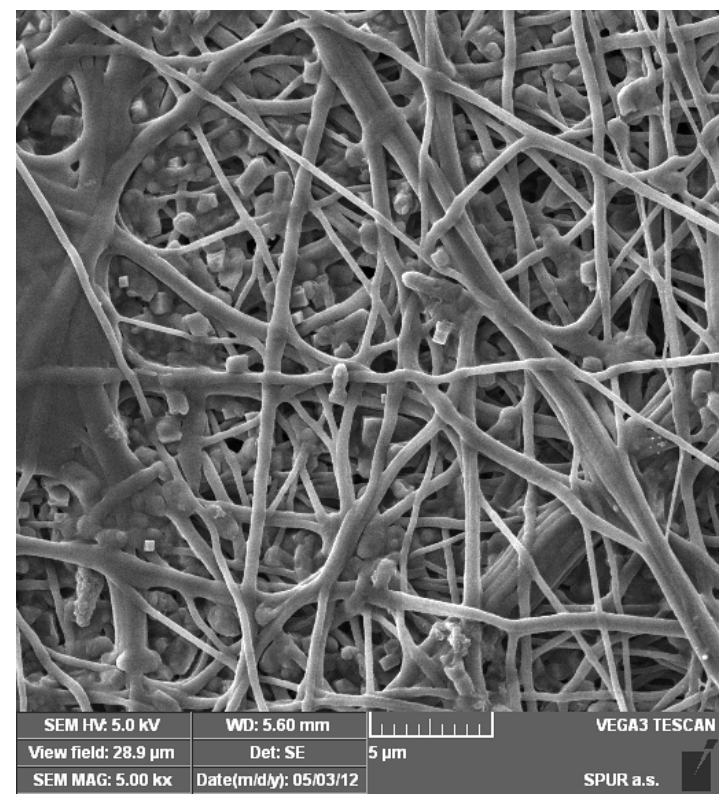

FIGURE 5. Sample 1 with captured bacteria inside the nanostructure, magnification 5,000×. 


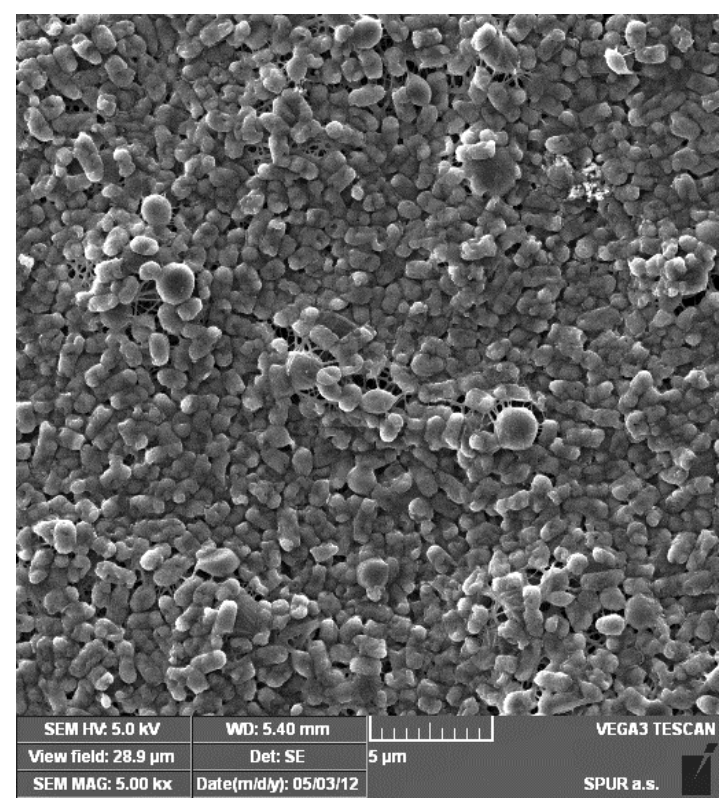

FIGURE 6. Filtration cake from Escherichia coli bacteria of Sample 2, magnification 5,000×.

To get an idea how the open and planar nanostructure morphology influences bacteria deactivation the digital image analysis of SEM picture for assessment of nanofibre diameter distribution (Figures 7 and 8) and pore size distribution (Figure 9) has been used. Open nanostructure of Sample 1 formed with thicker fibers $\left(D_{\text {average }}=\right.$ $202.1 \mathrm{~nm})$ and higher average pore size distribution $\left(D_{\text {AVERAGE }}=490.0 \mathrm{~nm}\right)$ in comparison with planar nanostructure of Sample 2 formed with thinner fibers $\left(D_{\text {average }}\right.$ $=117.9 \mathrm{~nm})$ and lower average pore size distribution $\left(D_{\mathrm{AVERAGE}}=274.9 \mathrm{~nm}\right)$ displays better antibacterial properties, the better contact with active oxygen species created from PC being the reason.

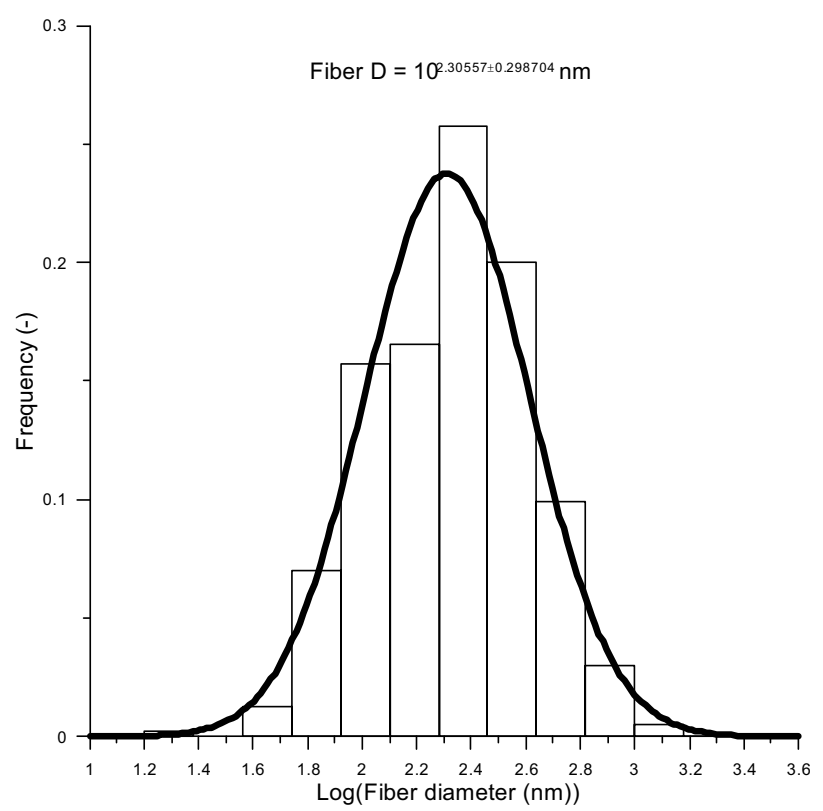

FIGURE 7. Nanofibre diameter distribution for Sample 1 having open nanostructures, $D_{\text {average }}=202.1 \mathrm{~nm}$. 


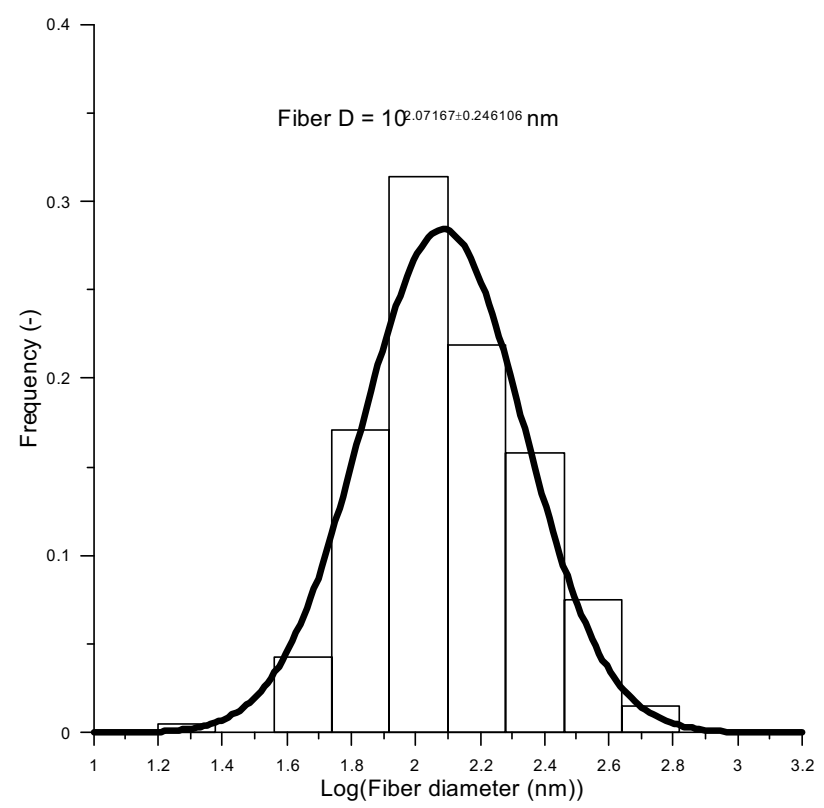

FIGURE 8. Nanofibre diameter distribution for Sample 2 having planar nanostructures, $D_{\text {average }}=117.9 \mathrm{~nm}$.

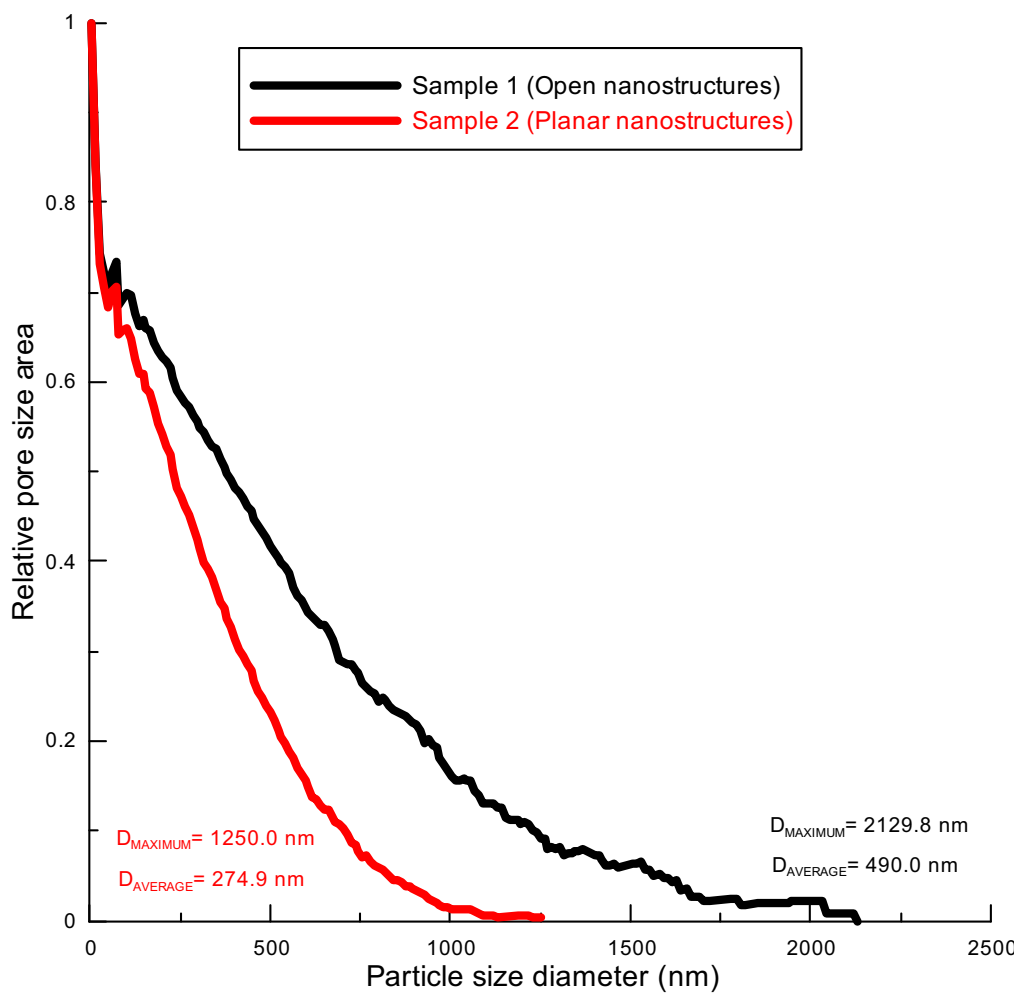

FIGURE 9. Pore size distributions for open and planar nanostructures. 


\section{CONCLUSIONS}

The work presents experimental procedures permitting preparation of antibacterial nanostructures containing phtalocyanine molecules firmly attached to PU chains by a covalent bond. A system of microbiological analyses was worked out allowing a demonstration of inhibition effects of PC on microorganisms. The morphology of antibacterial nanostructures has been found to be able to affect favourably the deactivation action of PC.

\section{ACKNOWLEDGMENTS}

This work has been supported by the grants of Czech Ministry of Industry and Trade No. FR-TI1/053 and Technology Agency of the Czech Republic No. TA01010356.

\section{REFERENCES}

1. L. Y. Lo and N. G. Stewart, World Patent WO 2012/064894 A1 (2012).

2. J. Mosinger, B. Mosinger, O. Jirsák and L. Mareš, Czech Patent CZ 303243 (2012).

3. D. Kimmer, M. Zatloukal, D. Petras, I. Vincent and P. Slobodian, AIP Conference Proceedings 1152, 305-311 (2009).

4. W. Sambaer, M. Zatloukal and D. Kimmer, AIP Conference Proceedings 1152, 312-322 (2009).

5. W. Sambaer, M. Zatloukal and D. Kimmer, Polymer Testing 29, 82-94 (2010).

6. W. Sambaer, M. Zatloukal and D. Kimmer, Chem. Eng. Sci. 66, 613-623 (2011).

7. W. Sambaer, M. Zatloukal and D. Kimmer, Chem. Eng. Sci. 82, 299-311 (2012).

8. H.-L. Wu, C.-H. Wang, C.-C.M. Ma, Y.-C. Chiu, M.-T. Chiang and C.-L. Chiang, Comp. Sci. and Tech. 67, 1854-1860 (2007).

9. D. Marie, F. Partensky, S. Jacquet and D. Vaulot, Appl. Environm. Microbiol. 63, 186-193 (1997).

10. G. Gregori, S. Citterio, A. Ghiani, M. Labra, S. Sgorbati, S. Brown and M. Denis, Appl. Environm. Microbiol. 67, 4662-4670 (2001). 